\title{
Multi-Class Procedure for Analysis of 50 Antibacterial Compounds in Eggshells Using Ultra-High-Performance Liquid Chromatography-Tandem Mass Spectrometry
}

\author{
Małgorzata Gbylik-Sikorska 1,*iD, Anna Gajda ${ }^{1}$, Ewelina Nowacka-Kozak ${ }^{1}$, Beata Łebkowska-Wieruszewska ${ }^{2} \mathbb{D}$ \\ and Andrzej Posyniak ${ }^{1}$ \\ 1 Department of Pharmacology and Toxicology, National Veterinary Research Institute (NVRI), \\ al. Partyzantow 57, 24-100 Pulawy, Poland; anna.gajda@piwet.pulawy.pl (A.G.); \\ ewelina.nowacka@piwet.pulawy.pl (E.N.-K.) aposyn@piwet.pulawy.pl (A.P.) \\ 2 Department of Pharmacology, Toxicology and Environmental Protection, University of Life Sciences, \\ 20-950 Lublin, Poland; lebkowska.wieruszewska@up.lublin.pl \\ * Correspondence: malgorzata.gbylik@piwet.pulawy.pl; Tel.: +48-81-889-3127
}

check for

updates

Citation: Gbylik-Sikorska, M.; Gajda,

A.; Nowacka-Kozak, E.;

Łebkowska-Wieruszewska, B.;

Posyniak, A. Multi-Class Procedure

for Analysis of 50 Antibacterial

Compounds in Eggshells Using

Ultra-High-Performance Liquid Chromatography-Tandem Mass Spectrometry. Molecules 2021, 26, 1373. https://doi.org/10.3390/ molecules 26051373

Academic Editor: Alessandra Gentili

Received: 15 February 2021

Accepted: 1 March 2021

Published: 4 March 2021

Publisher's Note: MDPI stays neutral with regard to jurisdictional claims in published maps and institutional affiliations.

Copyright: (c) 2021 by the authors. Licensee MDPI, Basel, Switzerland. This article is an open access article distributed under the terms and conditions of the Creative Commons Attribution (CC BY) license (https:/ / creativecommons.org/licenses/by/ $4.0 /)$.

\begin{abstract}
In this work, for the first time, Ultra-High-Performance Liquid Chromatography-Tandem Mass Spectrometry (UHPLC-MS/MS) method was developed for qualitative and quantitative analysis of veterinary antibiotics (cephalosporins, diaminopyrimidines, fluoro(quinolones), lincosamides, macrolides, penicillins, pleuromutilins, sulfonamides, tetracyclines, and sulfones) in hen eggshells. The sample preparation method is based on a liquid-liquid extraction with a mixture of metaphosphoric acid, ascorbic acid, EDTA disodium salt dihydrate, and acetonitrile. The chromatographic separation was performed on Luna ${ }^{\circledR}$ Omega Polar C18 10 column in gradient elution mode and quantitated in an $8 \mathrm{~min}$ run. Validation such as linearity, selectivity, precision, recovery, matrix effect, limit of quantification (LOQ), and limit of detection (LOD) was found to be within the acceptance criteria of the validation guidelines of the Commission Decision 2002/657/EC and EUR 28099 EN. Average recoveries ranged from $81-120 \%$. The calculated LOQ values ranged from 1 to $10 \mu \mathrm{g} / \mathrm{kg}$, the LOD values ranged from 0.3 to $4.0 \mu \mathrm{g} / \mathrm{kg}$, depending on analyte. The developed method has been successfully applied to the determination of antibacterial compounds in hen eggshell samples obtained from different sources. The results revealed that enrofloxacin, lincomycin, doxycycline, and oxytetracycline were detected in hen eggshell samples.
\end{abstract}

Keywords: eggshell; eggs; laying hens; UHPLC-MS/MS; antimicrobial; multi-class

\section{Introduction}

Hen eggshells make up about $10 \%$ of the total egg weight [1-3], which means that egg producers and the egg-using industry generate a huge amount of waste. The U.S. Environmental Protection Agency (EPA), ranked eggshell waste as the 15th major food industry pollution issue [4,5]. European Commission regulations also indicate that eggshell waste could be considered hazardous [5,6]. The European Union is the second-largest egg producer in the world, the first being China. Egg production in the EU increased by about half a million tonnes between 2010 and 2018 [7]. Annual egg production in the EU and the U.K. between 2010 and 2018 ranged from 6272 to 6940 ( $\times 1000$ tonnes). In 2019 and 2020, it is estimated that production was around 7065 and 7144 ( $\times 1000$ tonnes), respectively [8]. The future of food and agriculture-Alternative pathways to 2050 report, presents potential scenarios for global egg production in 2030 and 2050. The "towards sustainability scenario" (TSS) represents a proactive shift towards more sustainable food and farming systems in which global egg production is predicted to reach 85 million tons in 2030 and 91 million tons in 2050 [9]. The possibility of making use of such a large amount of biowaste is a very big challenge and an important element of environmental protection. 
Due to their unique composition and chemical structure, hen eggshells can be used in many industries. They consist of a mineralized shell (94\% calcium carbonate, $1 \%$ magnesium carbonate, $1 \%$ calcium phosphate, and trace elements) and a fibrous structure, the eggshell membrane [2,10-12]. Eggshell waste has found applications in the biofuel industry. Due to its high calcium carbonate content, they can be used as a heterogeneous catalyst in the transesterification process $[4,12,13]$. They can also be used to adsorb aquatic environment pollutants (toxic heavy metal, organic compounds, hydrogen sulfide, and dyes) [4,13-16]. Some researchers have found a way to use eggshells as a carbon dioxide sorbent in CCS (carbon capture and storage) [17]. Other authors have also reported the possibility of applying eggshells as bio-filters for polypropylene composites [18]. Another way to reuse biowaste such as eggshells is to use them as crop fertilizer. They provide a very good natural source of calcium, which helps some plants grow in calcium-deficient soil, and they balance the soil $\mathrm{pH}[3,4,13,19-21]$. Eggshells are a natural biomaterial, so they have found practical applications in various fields of medicine. They can be a source of calcium for the production of hydroxyapatite or nan-calcium citrate which can be used in orthopedics as a bone graft substitute $[4,6,11,13]$. In another application, they can be used as a nutritional additive in animal feed [3,4,13]. Moreover, because of their mineral content, especially calcium in a very easily bioavailable form, they can be used in the pharmaceutical industry to produce commercially available calcium supplements $[4,10,13,22]$, and in the food industry as a source of dietary calcium in fortified food $[23,24]$ or beverages [25]. In the available literature, we also found information about the preparation of eggshell powder at home and the selection of the correct amount for a natural calcium supplement [26].

There are four main systems of raising laying hens in the EU: in enriched cages (50.4\%), in barns (27.8\%), free-range (16.3), or organic (5.4) [27]. Large-scale animal husbandry results in the accumulation of numerous animals in a relatively small area, which contributes to the more rapid spread of bacterial diseases. Despite the application of the principles of biosecurity aimed at improving animal welfare and increasing animal resistance to possible infections, the use of antibiotics is often the only solution and the only effective way to reduce losses resulting from the spread of diseases. The use of veterinary drugs (antibiotics) in hens during the laying period is strictly limited. Some of these compounds are absorbed by the digestive tract of laying hens and transferred to the eggs [28]. To protect consumer health, the EU established maximum residue limits (MRLs) in eggs for only a few antibiotics (chlortetracycline, oxytetracycline, tetracycline, erythromycin, lincomycin, neomycin, tiamulin, tylosin, and colistin) [29]. The list of antibiotics approved by the Food and Drug Administration (FDA) for laying hens in the United States is also severely limited: bacitracin, erythromycin, hygromycin B, and tylosin [30]. Despite numerous restrictions and bans on the use of antibiotics, they are still sometimes used inappropriately or illegally in animal husbandry. Reports of the European Food Safety Authority (EFSA) from 2010 to 2018 showed that the number of non-compliant results for antibacterials (B1) in eggs were found in 93 samples [31-39]. The most frequently detected drugs were enrofloxacin $(n=34)$ and doxycycline $(n=24)$ as well as different sulfonamides $(n=20)$, all of which are prohibited in the EU for use in hens during the laying period. From 2015 to 2020, five cases of antibiotic detection in eggs and egg products were registered in the Rapid Alert System for Food and Feed (RASFF), of which enrofloxacin was the most frequently detected compound even at a concentration of $4236 \mu \mathrm{g} / \mathrm{kg}$ (in 2020). The presence of antibiotic residues in food and animal products such as eggs can lead to adverse effects, the most common of which are allergic reactions. Some antibiotics have the potential to cause immunopathological effects, nephropathy, hepatotoxicity, reproductive disorders, and even mutagenicity or carcinogenicity [40-43]. The most important adverse effect of antibiotic residues in food is the possibility of inducing antimicrobial resistance (AMR), which has become a significant global threat to human and animal health [44]. Global consumption of antimicrobials in food animal production was estimated at $63,151 \mathrm{t}$ in 2010 and is projected to rise by $67 \%$, to 105,596 t by 2030 . The Centers for Disease Control and Prevention (CDC) indicated that about 2,000,000 people were infected with antibiotic 
resistant bacteria, resulting in 23,000 deaths in the U.S. in 2013 [45]. If nothing changes, by 2050 up to 10,000,000 people per year could lose their lives [44].

The possibility of identifying a new source of antibiotic residues is an important element in preventing and eliminating antibiotic-resistant bacteria in the environment. This approach is in agreement with the "One Health" concept, which aims to strengthen collaboration in various sectors, such as public health, animal health, plant health, and the environment. Antibiotics used in human and veterinary medicine are made of the same or very similar molecules, and it can be expected that there will be a transfer of resistance between humans and animals either directly or via the environment. Therefore, detailed knowledge of new sources of antibiotic residues that could induce antimicrobial resistance in humans, animals, and the environment is of great importance for human health.

There are many papers in the literature on drug residues in eggs and their distribution between the yolk and egg white [28,46-49], but there are no studies on the possible transfer of drugs into the hen eggshells. The possibility of using eggshells as a food additive, supplement, animal feed additive, or plant fertilizer may risk exposing humans, animals, and the environment to antibiotic residues. Therefore, it is very important to study the possibility of transferring antibiotics into the eggshells.

This study presents a multi-class UHPLC-MS/MS analytical method for the qualitative and quantitative analysis of different commonly used veterinary antibiotics (cephalosporins, diaminopyrimidines, fluoro(quinolones), lincosamides, macrolides, penicillins, pleuromutilins, sulfonamides, tetracyclines, and sulfones) in hen eggshells. The developed method was validated according to international requirements: linearity, selectivity, specificity, precision (repeatability and within-laboratory reproducibility), and recovery. In addition, the limit of quantification (LOQ) and limit of detection (LOD) were estimated. This method has been successfully applied to the determination of antibiotic residues in hen eggshell samples obtained from different sources.

\section{Results and Discussion}

\subsection{Optimization of LC-MS/MS Conditions}

The UHPLC-MS/MS method for determining 50 analytes in eggshells was investigated. The multiple reaction monitoring (MRM) fragmentations were optimized for each analyte by direct infusion of analyte standard solution into the mass spectrometer. For quantitation and confirmation, generally, the protonated parent ions $[\mathrm{M}+\mathrm{H}]^{+}$and two transition products were monitored (Table 1 ). The mass source parameters such as declustering potential (DP), collision energy (CE), and dwell time were optimized in positive ionization mode separately for each analyte.

The LC separation was optimized for all studied compounds. Different mobile phases: water; $0.075 \%, 0.1 \%, 0.5 \%$ formic acid (water phase) with acetonitrile; methanol; mixture of acetonitrile with methanol (80:20, 50:50, 20:80 v/v); 0.05\%, 0.075\%, 0.1\% formic acid in acetonitrile; and $0.05 \%, 0.075 \% ; 0.1 \%$ formic acid in methanol (organic phase), using three different LC columns: Agilent ZORBAX SB-C18 column $(50 \mathrm{~mm} \times 2.1 \mathrm{~mm}, 1.8 \mu \mathrm{m})$; a Phenomenex Luna ${ }^{\circledR}$ Omega Polar C18 10 column $(100 \mathrm{~mm} \times 2.1 \mathrm{~mm}, 1.6 \mu \mathrm{m})$ and Phenomenex Luna C18 (2) 100A column $(50 \mathrm{~mm} \times 3.0,3 \mu \mathrm{m})$ were tested. Also, various gradient programs with different flow rates were tested to obtain optimal separation for all compounds in a relatively short runtime. The most efficient separation, best peak shape along with the highest possible signal intensity, was successfully achieved with the mobile phase consisted of $0.075 \%$ formic acid and $0.05 \%$ formic acid in acetonitrile combined with Luna ${ }^{\circledR}$ Omega Polar C18 10 column. Chromatograms of eggshell samples spiked with a mixture of 50 compounds are presented in Figure 1. 
Table 1. Summary of the MRM for analytes and MS/MS parameters.

\begin{tabular}{|c|c|c|c|c|c|c|}
\hline Group & Analyte & $\begin{array}{c}\text { Ion Transition } \\
1(\mathrm{~m} / \mathrm{z})\end{array}$ & $\begin{array}{c}\text { Ion Transition } \\
2(\mathrm{~m} / \mathrm{z})\end{array}$ & $\begin{array}{l}\text { Retention } \\
\text { Time (min) }\end{array}$ & $\mathrm{DP}(\mathrm{V})$ & $C E *(e V)$ \\
\hline \multirow{7}{*}{ cephalosporins } & CFQ & $529.0 / 134.0$ & $529.0 / 125.0$ & 2.28 & 50 & 25 \\
\hline & CFLO & $459.0 / 337.0$ & $459.0 / 152.0$ & 2.43 & 46 & 16 \\
\hline & CFZ & $455.0 / 323.0$ & $455.0 / 156.0$ & 2.71 & 50 & 15 \\
\hline & CFLE & $348.0 / 158.0$ & $348.0 / 106.0$ & 2.36 & 50 & 10 \\
\hline & CFPE & $646.0 / 530.0$ & $646.0 / 530.0$ & 2.93 & 50 & 35 \\
\hline & CFPI & $424.0 / 152.0$ & $424.0 / 124.0$ & 2.16 & 50 & 35 \\
\hline & CFT & $524.0 / 241.0$ & $524.0 / 125.0$ & 3.16 & 50 & 25 \\
\hline \multirow{2}{*}{ diaminopyrimidines } & TMP & $292.0 / 262.0$ & $292.0 / 231.0$ & 2.42 & 52 & 36 \\
\hline & TMP-d9(IS) & $300.0 / 234.0$ & - & 2.39 & 55 & 34 \\
\hline \multirow{11}{*}{ fluoro(quinolones) } & CIP & $332.0 / 314.0$ & $332.0 / 231.0$ & 2.48 & 65 & 28 \\
\hline & ENR & $360.0 / 342.0$ & $360.0 / 286.0$ & 2.59 & 100 & 33 \\
\hline & DIF & $400.0 / 382.0$ & $400.0 / 356.0$ & 2.75 & 50 & 30 \\
\hline & DAN & $358.0 / 340.0$ & $358.0 / 255.0$ & 2.53 & 60 & 33 \\
\hline & FLU & $262.0 / 244.0$ & $262.0 / 202.0$ & 3.75 & 44 & 25 \\
\hline & MAR & $363.0 / 345.0$ & $363.0 / 320.0$ & 2.42 & 70 & 30 \\
\hline & SAR & $385.0 / 368.1$ & $385.0 / 348.0$ & 2.72 & 50 & 31 \\
\hline & NOR & $320.0 / 302.0$ & $320.0 / 231.0$ & 2.45 & 50 & 30 \\
\hline & $\mathrm{OXO}$ & $262.0 / 244.0$ & $262.0 / 216.0$ & 3.33 & 53 & 25 \\
\hline & NAL & $233.0 / 215.0$ & $233.0 / 187.0$ & 3.69 & 42 & 30 \\
\hline & CIP-d8(IS) & $340.0 / 322.0$ & - & 2.46 & 60 & 29 \\
\hline lincosamides & LIN & $407.0 / 126.0$ & $407.2 / 359.0$ & 2.21 & 74 & 36 \\
\hline \multirow{7}{*}{ macrolides } & ERY & $734.0 / 576.0$ & $734.0 / 158.0$ & 3.13 & 75 & 28 \\
\hline & TYL & $916.0 / 174.0$ & $916.0 / 772.0$ & 3.22 & 110 & 51 \\
\hline & TLM & $806.6 / 577.4$ & $806.6 / 230.0$ & 2.30 & 61 & 33 \\
\hline & TIL & $869.0 / 696.0$ & $869.0 / 174.0$ & 2.83 & 135 & 56 \\
\hline & JOS & $828.0 / 173.0$ & $828.0 / 229.0$ & 2.63 & 80 & 46 \\
\hline & SPI & $843.0 / 540.0$ & $843.5 / 174.0$ & 2.61 & 120 & 44 \\
\hline & AZY(IS) & $749.0 / 591.0$ & - & 2.63 & 89 & 40 \\
\hline \multirow{10}{*}{ penicillins } & AMOX & $366.0 / 349.0$ & $366.0 / 208.0$ & 2.04 & 45 & 12 \\
\hline & PEN G & $335.0 / 160.0$ & $335.0 / 176.0$ & 3.51 & 60 & 17 \\
\hline & PEN V & $351.0 / 160.0$ & $351.0 / 114.0$ & 3.66 & 55 & 16 \\
\hline & AMPI & $350.0 / 106.0$ & $350.0 / 160.0$ & 2.34 & 58 & 27 \\
\hline & DICLOX & $470.0 / 160.0$ & $470.0 / 311.0$ & 2.75 & 50 & 20 \\
\hline & CLOX & $436.0 / 160.0$ & $436.0 / 277.0$ & 3.92 & 40 & 18 \\
\hline & NAF & $415.0 / 199.0$ & $415.0 / 171.0$ & 3.97 & 50 & 20 \\
\hline & OXA & $402.0 / 160.0$ & $402.0 / 243.0$ & 3.78 & 50 & 18 \\
\hline & PEN G-d7(IS) & $342.0 / 183.0$ & - & 3.46 & 35 & 20 \\
\hline & PIP(IS) & $540.0 / 398.0$ & - & 3.31 & 55 & 24 \\
\hline
\end{tabular}


Table 1. Cont.

\begin{tabular}{|c|c|c|c|c|c|c|}
\hline Group & Analyte & $\begin{array}{c}\text { Ion Transition } \\
1(\mathrm{~m} / \mathrm{z})\end{array}$ & $\begin{array}{c}\text { Ion Transition } \\
2(\mathrm{~m} / \mathrm{z})\end{array}$ & $\begin{array}{c}\text { Retention } \\
\text { Time (min) }\end{array}$ & DP (V) & $C E *(e V)$ \\
\hline \multirow{2}{*}{ pleuromutilins } & VAL & $565.0 / 263.0$ & $565.0 / 156.0$ & 3.49 & 45 & 40 \\
\hline & TIM & $494.0 / 192.0$ & $494.0 / 118.0$ & 3.43 & 128 & 30 \\
\hline \multirow{11}{*}{ sulfonamides } & SME & $265.0 / 156.0$ & $265.0 / 108.0$ & 2.72 & 40 & 25 \\
\hline & SMT & $279.0 / 156.0$ & $279.0 / 108.0$ & 3.20 & 50 & 25 \\
\hline & SDMX & $311.0 / 156.0$ & $311.0 / 108.0$ & 3.17 & 50 & 23 \\
\hline & SMA & $254.0 / 107.0$ & $254.0 / 155.0$ & 3.20 & 42 & 24 \\
\hline & SMM & $281.0 / 156.0$ & $281.0 / 108.0$ & 3.00 & 50 & 35 \\
\hline & SFT & $256.0 / 156.0$ & $256.0 / 108.0$ & 2.57 & 53 & 20 \\
\hline & SQX & $301.0 / 156.0$ & $301.0 / 108.0$ & 1.85 & 50 & 23 \\
\hline & SDX & $310.9 / 156.0$ & $310.9 / 108.0$ & 3.45 & 60 & 25 \\
\hline & SMP & $280.0 / 156.0$ & $280.0 / 108.0$ & 2.84 & 60 & 25 \\
\hline & SDZ & $251.0 / 156.0$ & $251.0 / 108.0$ & 2.55 & 53 & 22 \\
\hline & SFF(IS) & $315.0 / 156.0$ & - & 3.46 & 90 & 26 \\
\hline \multirow{5}{*}{ tetracyclines } & OTC & $461.0 / 426.0$ & $461.0 / 444.0$ & 2.45 & 50 & 28 \\
\hline & $\mathrm{TC}$ & $445.0 / 410.0$ & $445.0 / 427.0$ & 2.57 & 55 & 27 \\
\hline & СТC & $479.0 / 444.0$ & $479.0 / 462.0$ & 2.81 & 50 & 28 \\
\hline & DC & $445.0 / 428.0$ & $445.0 / 154.0$ & 2.87 & 60 & 23 \\
\hline & DMC(IS) & $465.0 / 448.0$ & - & 2.69 & 60 & 17 \\
\hline sulfones & DDS & $248.9 / 156.0$ & $248.9 / 108$ & 3.08 & 50 & 19 \\
\hline
\end{tabular}

* The CE value for ion transit 1 .

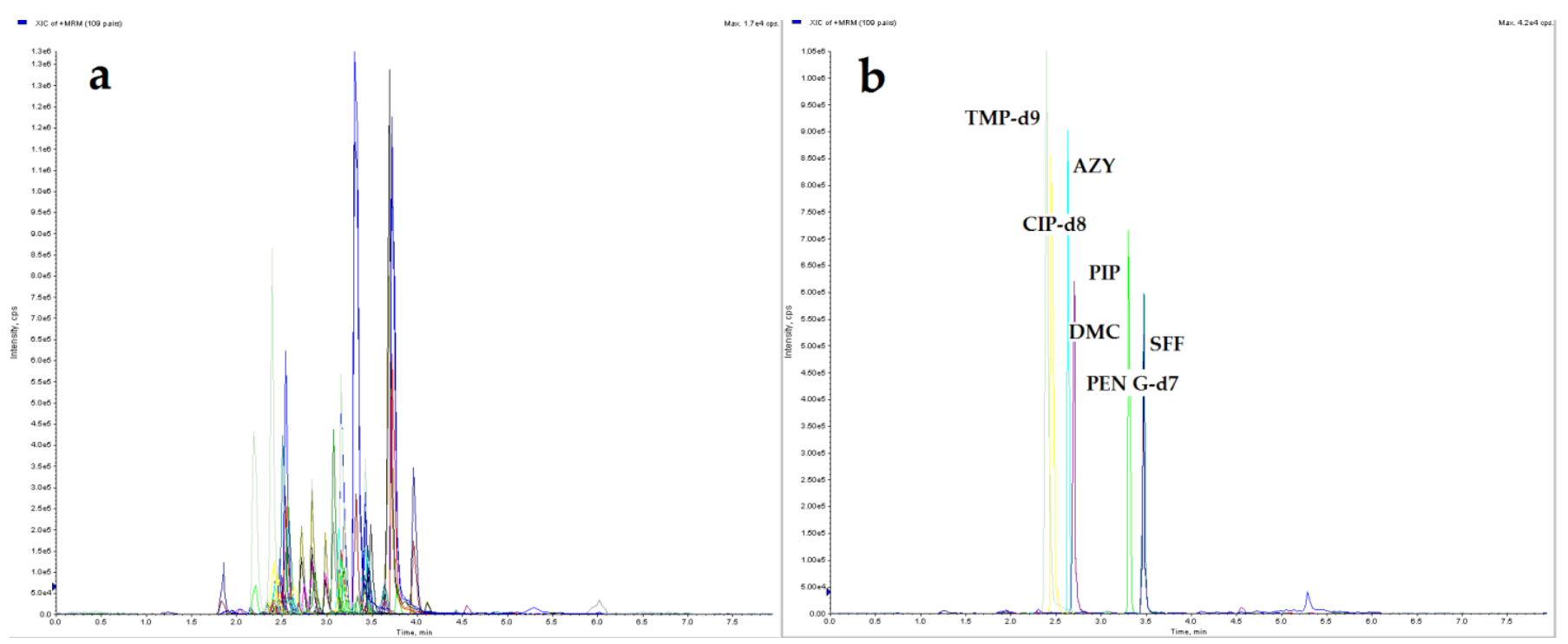

Figure 1. UHPLC-MS/MS XICs, (a) eggshell sample spiked with 50 analytes at $10 \mu \mathrm{g} / \mathrm{kg}$ and internal standard (IS) mixture at $20 \mu \mathrm{g} / \mathrm{kg}$; (b) blank eggshell sample with IS mixture at $20 \mu \mathrm{g} / \mathrm{kg}$. 


\subsection{Optimization of Sample Preparation}

In the first step, the sample preparation procedure was optimized. The avian eggshell is composed of about $96 \%$ calcium carbonate in the form of calcite and other non-organic components with an organic matrix (3.5\%), comprising the eggshell membranes and other constituents [1-3]. A very important stage was to improve the way of cleaning the eggshell of possible contamination and cross-contamination, and three different ways were tested: water, water then methanol, and methanol then water. The best results were obtained with the use of methanol followed by ultrapure water. This cleaning method also improved the separation of the shell from the membrane. Various ways of grinding eggshells were then tested: milling in the ball mixer mill; grinding from being frozen in liquid nitrogen, and blending. The best results were obtained from using the ball mixer mill, which ground the eggshells into a powder of similar grain size. When using the ball mill, it was necessary to select the appropriate parameters (grinding time, frequency, type, and ball size). The most efficient grinding was achieved by using a combination of 4 stainless steel balls of different sizes: 2 balls $\varnothing 10 \mathrm{~mm}$ and 2 balls $\varnothing 20 \mathrm{~mm}$. Three grams of hand-crushed eggshell were weighted into a $35 \mathrm{~mL}$ stainless steel grinding jar with the addition of the balls, and milling was carried at a frequency of $25 \mathrm{~Hz}$ at room temperature for $3 \mathrm{~min}$. Using the method of grinding eggshells frozen in liquid nitrogen, we obtained similar results, but this method was more expensive and time-consuming.

Different extraction procedures were then investigated to obtain the best analyte isolation from a specific matrix such as eggshells. So far in the available literature, there are no publications determining the antibacterial drug residues left in eggshells. Taking into account our previous experience in developing multi-class methods in different food matrices, we decided to test a different mixture of acids with organic solvents in the extraction step. The following extraction mixtures were tested: formic acid; metaphosphoric acid; ascorbic acid; citric acid; acetic acid (different $\mathrm{pH}$ and concentration) with acetonitrile and methanol. Initially, the results showed that the use of $1 \%$ metaphosphoric acid $\mathrm{pH}=5.0$ in combination with $0.5 \%$ ascorbic acid $\mathrm{pH}=4.0$ and acetonitrile showed the best recoveries and optimal results for all compounds. The use of formic acid, acetic acid, and citric acid in combination with acetonitrile or methanol did not give satisfactory results; in most cases, the extraction was not efficient. The use of a mixture of metaphosphoric acid with acetonitrile made it possible to isolate analytes from the matrix, but the addition of ascorbic acid improved the extraction of groups such as sulfonamides and fluoro(quinolones). Moreover, some analytes (tetracyclines, fluoro(quinolones)) can form chelates with metal ions (e.g., $\mathrm{Ca}^{2+}$, calcium carbonate), which is the primary component of the eggshell and contains about $40 \% \mathrm{Ca}^{2+}$ ions [50]. So, the addition of EDTA disodium salt dihydrate was tested to improve the recovery of these analytes, the recoveries for tetracyclines were significantly higher. Figure 2 summarizes the comparison of the mean recoveries between the different classes of compounds for the 5 selected best results achieved for the different extraction mixtures tested.

The extraction efficiency was enhanced by testing the use of an ultrasonic bath and a rotary stirrer at different time intervals ( $15 \mathrm{~min}, 30 \mathrm{~min}, 45 \mathrm{~min}, 1 \mathrm{~h}, 1.5 \mathrm{~h}$ ). The best results were obtained with a $45 \mathrm{~min}$ ultrasonic bath. After extraction and purification, the recovery of all analyzed compounds was determined in this study.

Additionally, to reduce possible interfering components in the final extract, two different syringe filter membranes (PTFE and PVDF) were tested. Finally, the use of PVDF filters allows for the best results to be achieved for all analytes without recovery reduction. 


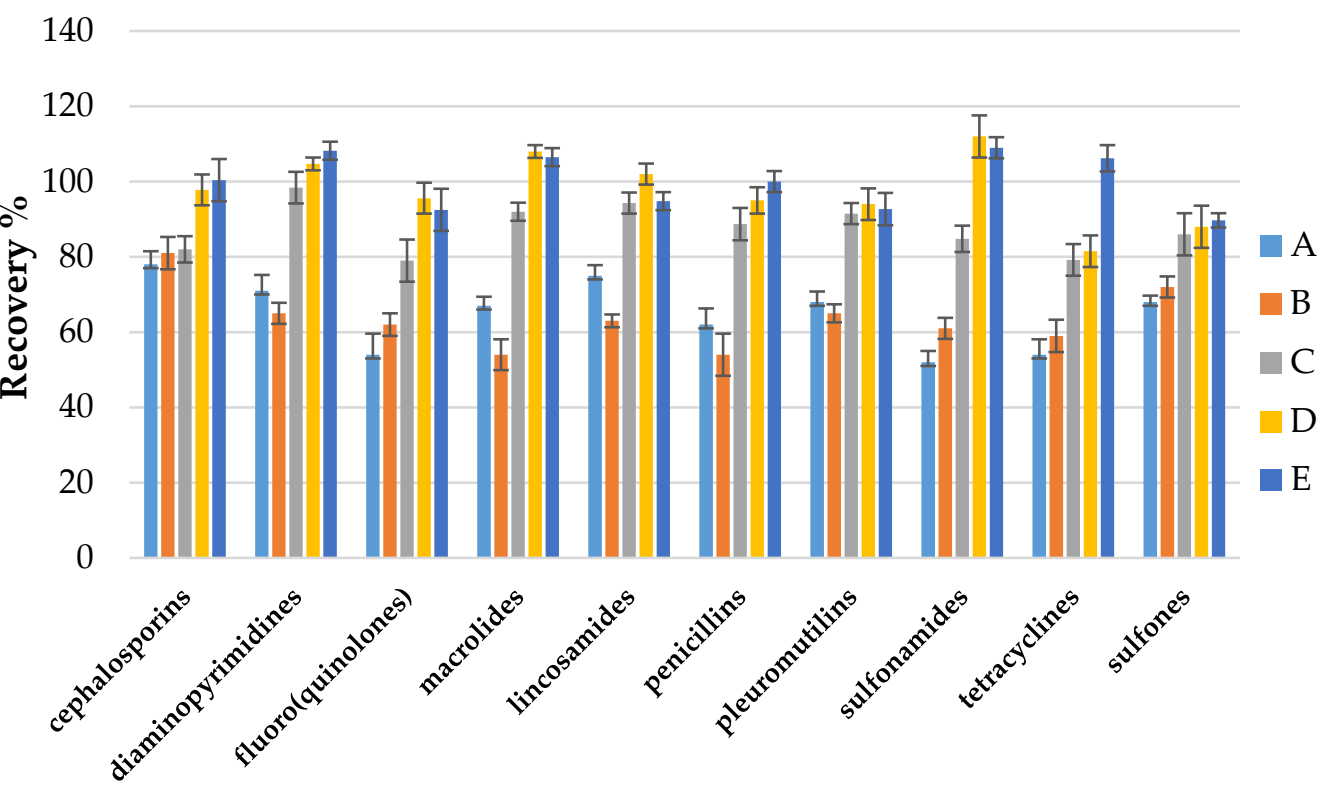

Figure 2. Effect of different extraction condition on recovery of 10 antibacterial compounds classes: (A) formic acid+ acetonitrile; (B) acetic acid + methanol; (C) metaphosphoric acid + acetonitrile; (D) metaphosphoric acid + ascorbic acid + acetonitrile; (E) metaphosphoric acid + ascorbic acid + EDTA + acetonitrile.

\subsection{Method Validation}

All of the matrix-matched calibration curves were linear (determination coefficient, $\mathrm{r}^{2}$ ), over the range of LOQ $-1000 \mu \mathrm{g} / \mathrm{kg}$, and were above 0.998 for all compounds. The within-laboratory reproducibility and repeatability were satisfactory for each analyte. The coefficients of variation (CVs, \%) for repeatability was lower than $10 \%$ and $15 \%$ for within-laboratory reproducibility, and the results are shown in Table 2. The specificity and selectivity of the method were verified by analyzing blank eggshell samples, which allowed us to verify that no peaks from endogenous compounds were detected in the retention time corresponding to each analyte or internal standard (IS). The average recoveries were in the range of $81-120 \%$. The LOQ and LOD values determined for the developed method are shown in Table 2, the calculated LOQs were in the range of 1 to $10 \mu \mathrm{g} / \mathrm{kg}$, the LODs were in the range of 0.3 to $4.0 \mu \mathrm{g} / \mathrm{kg}$.

Table 2. Validation results.

\begin{tabular}{ccccccc}
\hline Analyte & $\begin{array}{c}\text { Repeatability } \\
(\mathbf{C V}, \mathbf{\%})\end{array}$ & $\begin{array}{c}\text { Within-Lab } \\
\text { Reproducibility } \\
(\mathbf{C V}, \mathbf{\%})\end{array}$ & $\begin{array}{c}\text { LOQ } \\
(\boldsymbol{\mu g} / \mathbf{k g})\end{array}$ & $\begin{array}{c}\text { LOD } \\
(\mathbf{\mu g} / \mathbf{k g})\end{array}$ & Recovery * (\%) & Matrix Effect * (\%) \\
\hline CFQ & $8.8 \pm 1.0$ & $14.1 \pm 1.0$ & 5.0 & 1.0 & $119.1 \pm 3.6$ & $112.3 \pm 1.2$ \\
\hline CFLO & $9.1 \pm 1.1$ & $12.8 \pm 0.5$ & 5.0 & 1.0 & $106.4 \pm 5.4$ & $95.4 \pm 2.0$ \\
\hline CFZ & $7.9 \pm 1.0$ & $14.5 \pm 1.2$ & 5.0 & 1.0 & $81.6 \pm 3.2$ & $89.2 \pm 2.3$ \\
\hline CFLE & $6.4 \pm 1.1$ & $10.4 \pm 0.7$ & 5.0 & 1.0 & $83.1 \pm 3.5$ & $102.3 \pm 1.1$ \\
\hline CFPE & $6.8 \pm 1.0$ & $10.1 \pm 1.0$ & 5.0 & 1.0 & $97.7 \pm 4.1$ & $96.7 \pm 1.2$ \\
\hline CFPI & $7.1 \pm 1.1$ & $13.7 \pm 0.8$ & 5.0 & 1.0 & $103.1 \pm 3.5$ & $94.4 \pm 1.4$ \\
\hline CFT & $7.9 \pm 1.0$ & $12.1 \pm 1.1$ & 5.0 & 1.0 & $107.7 \pm 4.1$ & $119.7 \pm 1.3$ \\
\hline TMP & $8.2 \pm 1.1$ & $12.2 \pm 0.6$ & 5.0 & 1.0 & $92.2 \pm 5.5$ & $112.0 \pm 1.0$ \\
\hline CIP & $9.9 \pm 1.0$ & $13.1 \pm 1.1$ & 1.0 & 0.3 & $82.8 \pm 6.1$ & $125.3 \pm 2.0$ \\
\hline ENR & $7.1 \pm 1.1$ & $10.7 \pm 0.8$ & 1.0 & 0.3 & $105.7 \pm 3.6$ & $101.5 \pm 2.2$ \\
\hline DIF & $6.6 \pm 1.0$ & $10.1 \pm 1.3$ & 1.0 & 0.3 & $118.3 \pm 4.1$ & $88.6 \pm 2.1$ \\
\hline
\end{tabular}


Table 2. Cont.

\begin{tabular}{|c|c|c|c|c|c|c|}
\hline Analyte & $\begin{array}{c}\text { Repeatability *, } \\
(\mathrm{CV}, \%)\end{array}$ & $\begin{array}{c}\text { Within-Lab } \\
\text { Reproducibility *, } \\
(\mathrm{CV}, \%)\end{array}$ & $\begin{array}{c}\text { LOQ } \\
(\mu \mathrm{g} / \mathrm{kg})\end{array}$ & $\begin{array}{c}\text { LOD } \\
(\mu \mathrm{g} / \mathrm{kg})\end{array}$ & Recovery * $(\%)$ & Matrix Effect * $(\%)$ \\
\hline DAN & $7.8 \pm 1.1$ & $11.6 \pm 0.8$ & 1.0 & 0.3 & $102.8 \pm 3.6$ & $107.6 \pm 1.6$ \\
\hline FLU & $7.9 \pm 1.0$ & $12.1 \pm 1.4$ & 1.0 & 0.3 & $84.9 \pm 3.1$ & $107.1 \pm 2.2$ \\
\hline MAR & $7.3 \pm 1.1$ & $11.4 \pm 0.4$ & 1.0 & 0.4 & $104.5 \pm 5.8$ & $102.5 \pm 2.1$ \\
\hline SAR & $7.0 \pm 1.0$ & $11.1 \pm 1.1$ & 1.0 & 0.3 & $108.9 \pm 2.3$ & $89.4 \pm 1.4$ \\
\hline NOR & $8.9 \pm 1.1$ & $12.3 \pm 0.7$ & 1.0 & 0.4 & $97.1 \pm 5.6$ & $94.3 \pm 1.0$ \\
\hline LIN & $6.8 \pm 1.0$ & $12.1 \pm 1.0$ & 1.0 & 0.4 & $116.2 \pm 3.6$ & $96.7 \pm 1.3$ \\
\hline ERY & $6.7 \pm 1.1$ & $12.5 \pm 0.9$ & 1.0 & 0.4 & $105.5 \pm 5.6$ & $101.3 \pm 1.6$ \\
\hline TYL & $6.4 \pm 1.0$ & $12.1 \pm 1.1$ & 5.0 & 1.0 & $97.7 \pm 3.7$ & $124.7 \pm 1.1$ \\
\hline TIL & $6.4 \pm 1.1$ & $12.8 \pm 0.9$ & 5.0 & 1.0 & $99.5 \pm 4.2$ & $122.7 \pm 1.8$ \\
\hline JOS & $8.8 \pm 1.0$ & $13.1 \pm 0.6$ & 1.0 & 0.4 & $105.2 \pm 4.4$ & $104.4 \pm 0.9$ \\
\hline SPI & $8.4 \pm 1.0$ & $13.9 \pm 0.7$ & 5.0 & 1.0 & $116.0 \pm 3.9$ & $116.4 \pm 2.1$ \\
\hline TLM & $8.8 \pm 0.5$ & $14.6 \pm 0.4$ & 10.0 & 4.0 & $115.8 \pm 4.6$ & $111.4 \pm 1.7$ \\
\hline AMOX & $8.9 \pm 0.3$ & $11.2 \pm 0.4$ & 1.0 & 0.4 & $85.1 \pm 4.6$ & $89.7 \pm 1.3$ \\
\hline PEN G & $7.6 \pm 1.2$ & $11.4 \pm 0.9$ & 1.0 & 0.3 & $89.3 \pm 3.8$ & $103.1 \pm 0.8$ \\
\hline PEN V & $7.9 \pm 1.0$ & $10.1 \pm 1.1$ & 1.0 & 0.5 & $108.3 \pm 5.1$ & $116.3 \pm 0.6$ \\
\hline AMPI & $6.3 \pm 1.1$ & $10.6 \pm 0.7$ & 1.0 & 0.5 & $114.3 \pm 4.7$ & $127.3 \pm 1.4$ \\
\hline DICLOX & $7.9 \pm 1.0$ & $11.1 \pm 1.3$ & 1.0 & .03 & $105.2 \pm 2.7$ & $125.2 \pm 1.1$ \\
\hline CLOX & $9.1 \pm 1.1$ & $13.5 \pm 0.4$ & 1.0 & 0.5 & $86.4 \pm 4.6$ & $127.4 \pm 1.4$ \\
\hline NAF & $8.5 \pm 1.0$ & $11.1 \pm 1.0$ & 1.0 & 0.3 & $98.4 \pm 3.6$ & $91.3 \pm 2.1$ \\
\hline OXA & $8.0 \pm 1.1$ & $12.8 \pm 0.9$ & 1.0 & 0.3 & $93.3 \pm 2.1$ & $84.6 \pm 0.5$ \\
\hline TIM & $6.9 \pm 1.0$ & $11.1 \pm 0.4$ & 1.0 & 0.3 & $106.8 \pm 3.6$ & $111.2 \pm 1.2$ \\
\hline VAL & $6.5 \pm 1.1$ & $10.7 \pm 0.6$ & 1.0 & 0.4 & $96.9 \pm 3.1$ & $106.1 \pm 1.6$ \\
\hline SMT & $7.3 \pm 1.0$ & $11.1 \pm 1.1$ & 1.0 & 0.3 & $94.5 \pm 3.8$ & $106.6 \pm 1.1$ \\
\hline SME & $7.6 \pm 1.1$ & $11.8 \pm 0.5$ & 1.0 & 0.3 & $108.9 \pm 2.3$ & $118.7 \pm 1.3$ \\
\hline SDMX & $8.1 \pm 1.0$ & $12.1 \pm 1.3$ & 1.0 & 0.3 & $112.1 \pm 3.6$ & $97.6 \pm 0.9$ \\
\hline SMA & $7.2 \pm 1.1$ & $12.7 \pm 0.9$ & 1.0 & 0.3 & $111.6 \pm 5.6$ & $108.2 \pm 1.7$ \\
\hline SMM & $7.3 \pm 0.5$ & $12.1 \pm 0.4$ & 1.0 & 0.3 & $115.1 \pm 3.2$ & $97.6 \pm 2.1$ \\
\hline SFT & $8.7 \pm 1.1$ & $11.4 \pm 0.9$ & 1.0 & 0.4 & $85.8 \pm 3.8$ & $104.8 \pm 2.3$ \\
\hline SQX & $8.6 \pm 1.0$ & $13.5 \pm 1.1$ & 1.0 & 0.3 & $89.3 \pm 4.6$ & $81.9 \pm 0.8$ \\
\hline SDX & $7.1 \pm 1.1$ & $12.6 \pm 0.7$ & 1.0 & 0.3 & $85.7 \pm 4.9$ & $83.8 \pm 1.4$ \\
\hline SMP & $8.4 \pm 1.0$ & $11.9 \pm 0.7$ & 1.0 & 0.3 & $108.2 \pm 4.3$ & $98.2 \pm 1.0$ \\
\hline SDZ & $8.8 \pm 0.5$ & $10.6 \pm 0.4$ & 1.0 & 0.3 & $118.6 \pm 3.4$ & $97.9 \pm 0.8$ \\
\hline DC & $8.9 \pm 0.3$ & $10.2 \pm 0.4$ & 1.0 & 0.4 & $102.0 \pm 4.9$ & $88.5 \pm 1.0$ \\
\hline OTC & $7.6 \pm 1.2$ & $12.4 \pm 0.6$ & 1.0 & 0.4 & $91.4 \pm 3.6$ & $103.8 \pm 0.8$ \\
\hline $\mathrm{TC}$ & $6.4 \pm 1.1$ & $10.8 \pm 0.8$ & 1.0 & 0.4 & $93.3 \pm 2.8$ & $98.3 \pm 0.5$ \\
\hline CTC & $9.8 \pm 1.0$ & $13.1 \pm 1.1$ & 1.0 & 0.4 & $105.4 \pm 4.1$ & $95.9 \pm 1.2$ \\
\hline DDS & $6.6 \pm 1.1$ & $10.1 \pm 0.9$ & 1.0 & 0.4 & $85.5 \pm 3.6$ & $87.4 \pm 0.3$ \\
\hline
\end{tabular}


The matrix effects (MEs) were within the acceptable limits (81-128\%) after evaluating a mixture of 5 different lots of eggshells. The ME, \% value between 85 to $115 \%$ was considered as "not to be observed". The obtained results indicate that the ME was observed in 26\% of analytes (Table 2). Ion suppression was observed in most cases, ion enhancement was observed for some sulfonamides and OXA. To minimize and avoid the matrix effect, it is recommended that matrix-match calibration curves be used in each analysis of these substances in eggshell samples.

\subsection{Application of Real Samples}

To evaluated the applicability of the method, the eggshell samples $(n=20)$ were collected from eggs obtained from several different sources: 10 eggs were taken from two different experiments carried out on laying hens that received multiple oral doses of enrofloxacin $(n=3)$ or lincomycin $(n=3)$, and the eggs were collected on the 5th day of the administration of the antimicrobial drug. Other egg samples were obtained from two experiments in which doxycycline $(n=2)$ or oxytetracycline $(n=2)$ depletion and residues in eggs were determined after a single oral administration of the drug, and the eggs were collected 2 and 4 days after the end of the doxycycline and oxytetracycline administration, respectively. Eggshell samples $(n=10)$ obtained from eggs taken in 2020 as part of the National Residue Control Plan (NCP) for surveillance of veterinary drug residues in food of animal origin were also analyzed. The results of eggshell samples analysis obtained from experiments in which the drug was administered to animals proved that substances such as enrofloxacin, lincomycin, doxycycline, and oxytetracycline are distributed and present in the eggshell. The individual results are summarized in Table 3. This also confirms the need to control the antibacterial compound residues in eggshells, especially when they can be used in the food industry or as a calcium supplement. Selected sample chromatograms are shown in Figure 3.

Table 3. Results of eggshell samples analysis.

\begin{tabular}{|c|c|c|c|}
\hline Sample & Analyte & Concentration $(\mu \mathrm{g} / \mathrm{kg})$ & Rout/Dose $\left(\mathrm{mg} / \mathrm{kg} \mathrm{bw}{ }^{*}\right) /$ Time of Treatment (Days) \\
\hline \multirow{2}{*}{1 (experiment 1 ) } & ENR & 587 & \multirow{2}{*}{ oral $/ 10 / 5$} \\
\hline & CIP & 18.3 & \\
\hline \multirow{2}{*}{2 (experiment 1 ) } & ENR & 423 & \multirow{2}{*}{ oral $/ 10 / 5$} \\
\hline & CIP & 10.5 & \\
\hline \multirow{2}{*}{3 (experiment 1$)$} & ENR & 634 & \multirow{2}{*}{ oral $/ 10 / 5$} \\
\hline & $\mathrm{CIP}$ & 12.4 & \\
\hline 4 (experiment 2) & LIN & 12.0 & oral $/ 20 / 5$ \\
\hline 5 (experiment 2) & LIN & 9.6 & oral $/ 20 / 5$ \\
\hline 6 (experiment 2 ) & LIN & 15.4 & oral $/ 20 / 5$ \\
\hline 7 (experiment 3) & DC & 17.5 & oral $/ 10 / 1$ \\
\hline 8 (experiment 3 ) & DC & 14.6 & oral/10/1 \\
\hline 9 (experiment 4) & OTC & 26.4 & oral $/ 20 / 1$ \\
\hline 10 (experiment 4) & OTC & 18.7 & oral $/ 20 / 1$ \\
\hline 11 (NRCP) & nd & - & - \\
\hline 12 (NRCP) & nd & - & - \\
\hline 13 (NRCP) & nd & - & - \\
\hline 14 (NRCP) & nd & - & - \\
\hline 15 (NRCP) & nd & - & - \\
\hline 16 (NRCP) & nd & - & - \\
\hline
\end{tabular}


Table 3. Cont.

\begin{tabular}{cccc}
\hline Sample & Analyte & Concentration $(\mu \mathrm{g} / \mathrm{kg})$ & Rout/Dose $\left(\mathrm{mg} / \mathbf{k g}\right.$ bw $\left.{ }^{*}\right) /$ Time of Treatment $($ Days $)$ \\
\hline $17(\mathrm{NRCP})$ & nd & - & - \\
\hline $18(\mathrm{NRCP})$ & nd & - & - \\
\hline $19(\mathrm{NRCP})$ & nd & - & - \\
\hline $20(\mathrm{NRCP})$ & nd & - & - \\
\hline
\end{tabular}

${ }^{*}$ bw $=$ body weight.

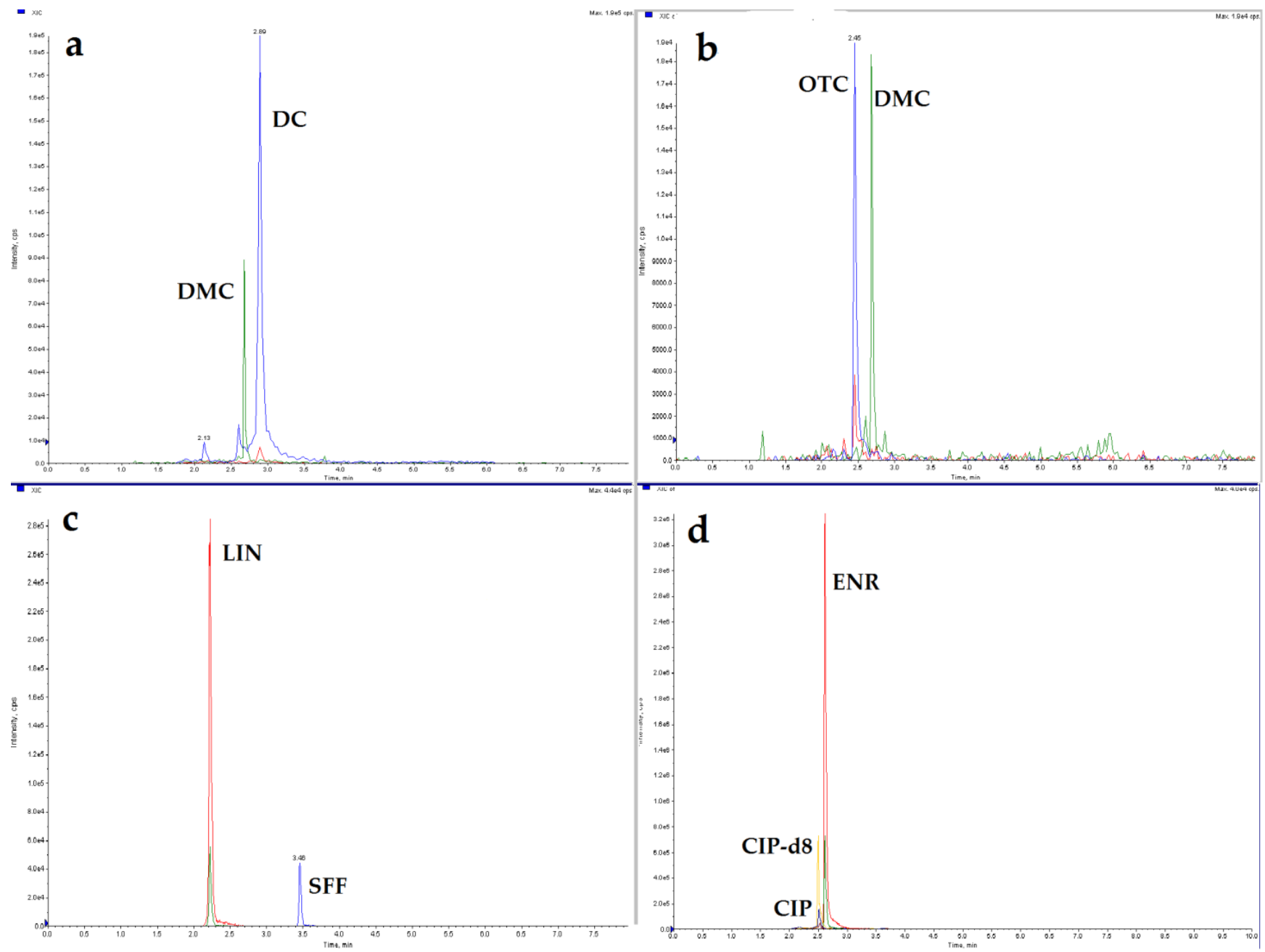

Figure 3. Chromatograms of real eggshell samples: (a) doxycycline $17.5 \mu \mathrm{g} / \mathrm{kg}$; (b) oxytetracycline $26.4 \mu \mathrm{g} / \mathrm{kg}$; (c) lincomycin $12.0 \mu \mathrm{g} / \mathrm{kg}$; (d) enrofloxacin $587 \mu \mathrm{g} / \mathrm{kg}$; and ciprofloxacin $18.3 \mu \mathrm{g} / \mathrm{kg}$.

\section{Materials and Methods}

\subsection{Chemical and Reagents}

Acetonitrile and methanol, LC-MS-grade, were obtained from J.T. Baker (Deventer, The Netherlands), EDTA disodium salt dihydrate and sodium hydroxide were purchased from POCH, Gliwice, Poland; ascorbic acid, metaphosphoric acid and formic acid ( $\geq 95 \%$ for LC-MS) came from Sigma-Aldrich (St. Louis, MO, USA). Syringe filters PVDF $(0.22 \mu \mathrm{m})$ were purchased from Restek (Bellefonte, PA, USA). Ultrapure water, the conductivity of at least $18 \mathrm{M} \Omega / \mathrm{cm}$ was prepared with the Millipore purification system.

The cefquinome (CFQ), cefalonium (CFLO), cefazolin (CFZ), cephalexin (CFLE), cefoperazone (CFPE), cefapirin (CFPI), ceftiofur (CFT), trimethoprim (TMP), trimethoprim-d9 
(TMP-d9), ciprofloxacin (CIP), enrofloxacin (ENR), danofloxacin (DAN), difloxacin (DIF), flumequine (FLU), marbofloxacin (MAR), sarafloxacin (SAR), norfloxacin (NOR), oxolinic acid (OXO), nalidixic acid (NAL), ciprofloxacin-d8 (CIP-d8) lincomycin (LIN), josamycin (JOS) erythromycin (ERY), spiramycin (SPI), tylosin (TYL), tulathromycin (TLM), tilmicosin (TIL), azytromycin (AZY) amoxicillin (AMOX), penicillin G (PEN G), penicillin V (PEN V), ampicillin (AMPI), dicloxacillin (DICLOX), cloxacillin (CLOX), nafcillin (NAF), oxacillin (OXA), penicillin G-d7 (PEN G-d7), piperacillin (PIP), valnemulin (VAL), tiamulin (TIM), sulfamerazine (SME), sulfamethazine (SMT), sulfadimethoxine (SDMX), sulfamethoxazole (SMA), sulfamonomethoxine (SMM), sulfathiazole (SFT), sulfaquinoxaline (SQX), sulfadoxine (SDX), sulphamethoxypyridazine (SMP), sulfadiazine (SDZ), sulfafenazole (SFF), doxycycline (DC), tetracycline (TC), oxytetracycline (OTC), chlortetracycline (CTC), demeclocycline (DMC), and dapson (DDS) were purchased from Sigma-Aldrich (St. Louis, MO, USA).

\subsection{Preparation of the Standard Stock Solutions and Working Solutions}

Stock standard solutions (1000 $\mu \mathrm{g} / \mathrm{mL}$ ) of cephalosporins and penicillins were prepared in ultrapure water and stored in polypropylene vessels. Diaminopyrimidines, lincosamides, macrolides, pleuromutilins, sulfonamides, sulfones, and tetracyclines were dissolved in methanol, fluoro(quinolones) were dissolved in methanol with the addition of $1 \mathrm{M}$ sodium hydroxide $(99: 1, v / v)$, and were stored in glass vessels. All individual stock standard solutions were stable for at least 6 months when retained in a dark place at $-18{ }^{\circ} \mathrm{C}$. A mixture of working solutions $(1 \mu \mathrm{g} / \mathrm{mL})$ and mixture of internal standard (IS) solutions was obtained by dilution in ultrapure water and stored at $4-8{ }^{\circ} \mathrm{C}$ for 1 month.

\subsection{Sample Preparation}

In the sample pretreatment step, eggshells were first cleaned with methanol and ultrapure water to remove contaminants; then, the eggshell membrane was removed to reduce possible cross-contamination. The eggshells thus prepared were dried at room temperature for $1 \mathrm{~h}$, transferred to string bags and hand crushed. Three grams of crushed eggshell were weighed in a stainless steel $35 \mathrm{~mL}$ grinding jar with the addition of 4 stainless steel, 2 balls $\varnothing 10 \mathrm{~mm}$ and 2 balls $\varnothing 20 \mathrm{~mm}$. Milling was carried out in the ball mixer mill MM 400 (Retsch-Verder Scientific, Haan, Germany) at a frequency of $25 \mathrm{~Hz}$ at room temperature for $3 \mathrm{~min}$. Such milled eggshells $(2 \mathrm{~g})$ were weighed into $10 \mathrm{~mL}$ centrifuge tubes; then, $40 \mu \mathrm{L}$ of IS mixture $(1 \mu \mathrm{g} / \mathrm{mL})$ was added, mixed, and stored in a dark place at $4-8{ }^{\circ} \mathrm{C}$ for $15 \mathrm{~min}$. After incubation, $750 \mu \mathrm{L}$ of $1 \%$ metaphosphoric acid $\mathrm{pH}=5.0,500 \mu \mathrm{L}$ $0.5 \%$ ascorbic acid $\mathrm{pH}=4.0,200 \mu \mathrm{L}$ 0.1M EDTA disodium salt dihydrate, and $8 \mathrm{~mL}$ of acetonitrile were added to the eggshells. The samples were vortexed for $30 \mathrm{~s}$ and put in an ultrasonic bath (Bandelin SONOREX ${ }^{\mathrm{TM}}$, Berlin, Germany) for $45 \mathrm{~min}$ at room temperature. Then, the samples were centrifuged at $2930 \times \mathrm{rcf}$ for $10 \mathrm{~min}$, temperature: $4^{\circ} \mathrm{C}$ (Centrifuge 4-16KS, Sigma, Darmstadt, Germany). The supernatants were evaporated to dryness at $45 \pm 5{ }^{\circ} \mathrm{C}$ under a stream of nitrogen, redissolved in $500 \mu \mathrm{L}$ of ultrapure water, and filtered by syringe filters ( $0.22 \mu \mathrm{m}$ PVDF) into LC vials prior to LC-MS/MS analysis.

\subsection{LC-MS/MS Analysis}

The Shimadzu Nexera X2 (Shimadzu, Kyoto, Japan) ultra-high-performance liquid chromatograph (UHPLC) system coupled to the QTRAP ${ }^{\circledR} 4500$ triple-quadrupole mass spectrometer (Sciex, Framingham, MA, USA) was used for sample analysis.

The UHPLC system was equipped with a Luna ${ }^{\circledR}$ Omega $1.6 \mu \mathrm{m}$ Polar C18 10 column $(100 \mathrm{~mm} \times 2.1 \mathrm{~mm}$, Phenomenex, Torrance, CA, USA) integrated with a guard column of the same type at $35{ }^{\circ} \mathrm{C}$. The mobile phase consisted of two eluents, $0.075 \%$ formic acid (A) and $0.05 \%$ formic acid in acetonitrile (B). The samples were separated under the following gradient conditions: $92 \%$ A (0.01-4.00 $\mathrm{min}), 90 \% \mathrm{~B}(4.01-6.30 \mathrm{~min})$, and $92 \%$ A (6.31-8.00 min), at a flow rate of $0.32 \mathrm{~mL} / \mathrm{min}$. A volume of $3 \mu \mathrm{L}$ of sample extract was injected. The mass spectrometric analysis was performed using triple-quadrupole 
detection in positive ion mode (ESI+). The instrument was set to collect data in multiple reaction monitoring mode (MRM) for quantification. The ion transitions and mass parameters monitored for each analyte are listed in Table 1. The following MS/MS parameters were used for multi-compound analysis: source temperature $=470{ }^{\circ} \mathrm{C}$; IonSpray voltage $=5500 \mathrm{~V}$; Curtain Gas $=20 \mathrm{psi}$; ion source gas $1=40 \mathrm{psi}$; ion source gas $2=50 \mathrm{psi}$; Entrance potential $=10 \mathrm{~V}$.

\subsection{Method Validation}

The method was validated according to the Commission Decision 2002/657/EC [51]. Linearity, selectivity, specificity, precision (repeatability and within-laboratory reproducibility), and recovery were evaluated. In addition, the limit of quantification (LOQ) and limit of detection (LOD) were estimated (EUR 28,099 EN) [52]. Linearity in matrix (antibiotics free eggshells) was tested in the range LOQ-1000 $\mu \mathrm{g} / \mathrm{kg}$ at 7 concentration levels: LOQ $(1.0,5.0,10.0$, depending on the analyte); 20, 50, 100, 200, 500, and $1000 \mu \mathrm{g} / \mathrm{kg}$. Selectivity and specificity were investigated by analysis of 6 different blank eggshell samples to test for potential interference with endogenous substances. Method repeatability was estimated after analyzing 6 samples spiked at 3 concentration levels: 10, 50, and $100 \mu \mathrm{g} / \mathrm{kg}$ by the same operator on the same day with the same instrument, after which CVs (\%) were calculated. The within-laboratory reproducibility was calculated as an overall CV $(\%)$ of the results, which obtained after an analysis of fortifying another two sets of blank samples with the same concentration levels. It was repeated on two different days with the same instrument and different operators. The average recovery was evaluated in the same experiment as repeatability by comparing the mean measured concentration with the fortified concentration of the samples. The LOD was determined at the signal-to-noise ratio $(\mathrm{S} / \mathrm{N}) \approx 3$; the LOQ was defined as the lowest validated concentration with the $\mathrm{S} / \mathrm{N}>10$. The matrix effect (ME, \%) was assessed comparing matrix-matched standards (the signal intensity of a sample extract fortified after extraction-IM) with standards in solvent (the signal intensity of fortified water- $I W$ ) at the corresponding concentration of $50 \mu \mathrm{g} / \mathrm{kg}$, which is expressed by the following Equation (1):

$$
\operatorname{ME}(\%)=\frac{I M}{I W} \times 100
$$

\section{Conclusions}

The possibility of identifying a new source of antibiotic residues is one element in preventing and eliminating antimicrobial resistance in the environment. A first attempt was made to develop a multi-class UHPLC-MS/MS method for determining 50 different antimicrobial compounds in hen eggshells to carry out relevant studies. The presented method has been successfully validated in accordance with Commission Decision 2002/657/EC and guidelines EUR 28,099 EN. It was found that this analytical method can be successfully used in the analysis of antibacterial residues in hen eggshells. Moreover, according to our knowledge, it is the first time that antibacterial residues have been detected in eggshell samples. Studies conducted on real eggshell samples may provide evidence for the possibility of drug transfer into the eggshells. Conducting further research into the potential for the distribution of various veterinary drugs into eggshells is of great importance to human health.

Author Contributions: Conceptualization, M.G.-S.; methodology, M.G.-S.; validation, M.G.-S., A.G., E.N.-K., and B.E.-W.; investigation, M.G.-S.; writing—original draft preparation, M.G.-S.; writingreview and editing, M.G.-S. and A.P. All authors have read and agreed to the published version of the manuscript.

Funding: This research received no external funding.

Institutional Review Board Statement: Not applicable.

Informed Consent Statement: Not applicable. 
Data Availability Statement: The data presented in this study are available in the manuscript.

Acknowledgments: The authors are grateful to Magdalena Bilecka for her support in carrying out experiments and sample preparation for UHPLC-MS/MS analysis.

Conflicts of Interest: The authors declare no conflict of interest.

Sample Availability: Samples are not available.

\section{References}

1. Nys, Y.; Gautron, J.; Garcia-Ruiz, J.M.; Hincke, M.T. Avian eggshell mineralization: Biochemical and functional characterization of matrix proteins. Comptes Rendus Palevol 2004, 3, 549-562. [CrossRef]

2. Ketta, M.; Tůamová, E. Eggshell structure, measurements, and quality-affecting factors in laying hens: A review. Czech J. Anim. Sci. 2016, 61, 299-309. [CrossRef]

3. King'ori, A.M. A Review of the uses of poultry eggshells and shell membranes. Int. J. Poult. Sci. 2011, 10, 908-912. [CrossRef]

4. Waheed, M.; Yousaf, M.; Shehzad, A.; Inam-Ur-Raheem, M.; Khan, M.K.I.; Khan, M.R.; Ahmad, N.; Abdullah; Aadil, R.M. Channelling eggshell waste to valuable and utilizable products: A comprehensive review. Trends Food Sci. Technol. 2020, 106, 78-90. [CrossRef]

5. Owuamanam, S.; Cree, D. Progress of Bio-Calcium Carbonate Waste Eggshell and Seashell Fillers in Polymer Composites: A Review. J. Compos. Sci. 2020, 4, 70. [CrossRef]

6. Mignardi, S.; Archilletti, L.; Medeghini, L.; De Vito, C. Valorization of Eggshell Biowaste for Sustainable Environmental Remediation. Sci. Rep. 2020, 10, 1-10. [CrossRef] [PubMed]

7. van Horne, P.L.M. Competitiveness of the EU Egg Industry. International Comparison Base Year 2013; Wageningen Economic Research: Wageningen, The Netherlands, 2013; ISBN 9789086156962.

8. European Union. EU Agricultural Outlook 2017-2030; European Union: Belgium, Brussels, 2017; ISBN 9789276153825.

9. Food and Agriculture Organization of the United Nations. The Future of Food and Agriculture Alternative Pathways to 2050: Supplementary Material; FAO: Rome, Italy, 2018; ISBN 978-92-5-130982-7.

10. Schaafsma, A.; Pakan, I.; Hofstede, G.J.H.; Muskiet, F.A.J.; Van Der Veer, E.; De Vries, P.J.F. Mineral, amino acid, and hormonal composition of chicken eggshell powder and the evaluation of its use in human nutrition. Poult. Sci. 2000, 79, 1833-1838. [CrossRef]

11. Abdulrahman, I.; Tijani, H.I.; Mohammed, B.A.; Saidu, H.; Yusuf, H.; Ndejiko Jibrin, M.; Mohammed, S. From Garbage to Biomaterials: An Overview on Egg Shell Based Hydroxyapatite. J. Mater. 2014, 2014, 1-6. [CrossRef]

12. Laca, A.; Laca, A.; Díaz, M. Eggshell waste as catalyst: A review. J. Environ. Manag. 2017, 197, 351-359. [CrossRef]

13. Faridi, H.; Arabhosseini, A. Application of eggshell wastes as valuable and utilizable products: A review. Res. Agric. Eng. 2018, 64, 104-114.

14. Tsai, W.T.; Hsien, K.J.; Hsu, H.C.; Lin, C.M.; Lin, K.Y.; Chiu, C.H. Utilization of ground eggshell waste as an adsorbent for the removal of dyes from aqueous solution. Bioresour. Technol. 2008, 99, 1623-1629. [CrossRef] [PubMed]

15. Setiawan, B.D.; Rizqi, O.; Brilianti, N.F.; Wasito, H. Nanoporous of waste avian eggshell to reduce heavy metal and acidity in water. Sustain. Chem. Pharm. 2018, 10, 163-167. [CrossRef]

16. Buksh, N.; Yun, C.; Ping, X.; Jhatial, G.H.; Yanhai, S. Chicken Eggshell as a Potential Eco-friendly, Low-cost Sorbent: A Mini Review. J. Environ. Earth Sci. 2018, 8, 28-39.

17. He, S.; Hu, Y.; Hu, T.; Ma, A.; Jia, Q.; Su, H.; Shan, S. Investigation of CaO-based sorbents derived from eggshells and red mud for $\mathrm{CO}_{2}$ capture. J. Alloys Compd. 2017, 701, 828-833. [CrossRef]

18. Bashir, A.S.M.; Manusamy, Y. Characterization of Raw Egg Shell Powder (ESP) as A Good Bio-filler. J. Eng. Res. Technol. 2015, 2, 56-60.

19. Radha, T.; Karthikeyan, G. Hen Eggshell Waste as Fertilizer for the Growth of Phaseolus Vulgaris (Cow Pea Seeds). Res. J. Life Sci. Bioinformatics Pharm. Chem. Sci. 2019, 5, 398-406.

20. Khairnar, M.D.; Nair, S.S. Study on Eggshell and Fruit Peels as a Fertilizer. In Proceedings of the International Conference on Sustainable Development (ICSD 2019), New York, NY, USA, 24-25 September 2019; Novateur Publication: Pune, India, 2019; pp. 25-27.

21. da Silveira, N.H.; Rabêlo, F.H.S.; de Rezende, A.V.; Rabelo, C.H.S.; Bianchini, H.C. Eggshell as a source of calcium in the production, nutrition and bromatological composition of "Piatã "and "Marandu "grasses. Rev. Bras. Eng. Agric. e Ambient. 2016, 20, 113-118. [CrossRef]

22. Waheed, M.; Butt, M.S.; Shehzad, A.; Adzahan, N.M.; Shabbir, M.A.; Rasul Suleria, H.A.; Aadil, R.M. Eggshell calcium: A cheap alternative to expensive supplements. Trends Food Sci. Technol. 2019, 91, 219-230. [CrossRef]

23. Ray, S.; Barman, A.K.; Roy, P.K.; Singh, B.K. Chicken eggshell powder as dietary calcium source in chocolate cakes. Pharma Innov. J. 2017, 6, 1-4.

24. Bartter, J.; Diffey, H.; Yeung, Y.H.; O’Leary, F.; Häsler, B.; Maulaga, W.; Alders, R. Use of chicken eggshell to improve dietary calcium intake in rural sub-Saharan Africa. Matern. Child Nutr. 2018, 14, 1-10. [CrossRef] 
25. Lachowicz, S.; Oszmiański, J.; Wilczyńska, M.; Zaguła, G.; Saletnik, B.; Puchalski, C. Impact mineralization of chokeberry and cranberry fruit juices using a new functional additive on the protection of bioactive compounds and antioxidative properties. Molecules 2020, 25, 659. [CrossRef]

26. Brun, L.R.; Lupo, M.; Delorenzi, D.A.; Di Loreto, V.E.; Rigalli, A. Chicken eggshell as suitable calcium source at home. Int. J. Food Sci. Nutr. 2013, 64, 740-743. [CrossRef] [PubMed]

27. Augère-Granier, M.-L. The EU poultry meat and egg sector-Main features, challenges and prospects. EPRS Eur. Parliam. Res. Serv. 2019, 24. [CrossRef]

28. Kan, C.A.; Petz, M. Residues of veterinary drugs in eggs and their distribution between yolk and white. J. Agric. Food Chem. 2000, 48, 6397-6403. [CrossRef] [PubMed]

29. European Parliament and the Council of the European Union Commission Regulation (EU) No 37/2010. Off. J. Eur. Union 2010, L15, 1-27.

30. Marmulak, T.; Tell, L.A.; Gehring, R.; Baynes, R.E.; Vickroy, T.W.; Riviere, J.E. FARAD Digest: Egg residue considerations during the treatment of backyard poultry. Vet Med Today FARAD Digest. 2015, 247, 1388-1395.

31. Report for 2010 on the Results from the Monitoring of Veterinary Medicinal Product Residues and other Substances in Live Animals and Animal Products; EFSA Supporting Publication: Parma, Italy, 2012; Volume 9.

32. Report for 2011 on the Results from the Monitoring of Veterinary Medicinal Product Residues and Other Substances in Live Animals and Animal Products; EFSA Supporting Publication: Parma, Italy, 2013; Volume 10.

33. Report for 2012 on the Results from the Monitoring of Veterinary Medicinal Product Residues and Other Substances in Live Animals and Animal Products; EFSA Supporting Publication: Parma, Italy, 2014; Volume 11.

34. Report for 2013 on the Results from the Monitoring of Veterinary Medicinal Product Residues and Other Substances in Live Animals and Animal Products; EFSA Supporting Publication: Parma, Italy, 2015; Volume 12.

35. Report for 2014 on the Results from the Monitoring of Veterinary Medicinal Product Residues and Other Substances in Live Animals and Animal Products; EFSA Supporting Publication: Parma, Italy, 2016; Volume 13.

36. Report for 2014 on the Results from the Monitoring of Veterinary Medicinal Product Residues and Other Substances in Live Animals and Animal Products; EFSA Supporting Publication: Parma, Italy, 2017; Volume 14.

37. Report for 2016 on the Results from the Monitoring of Veterinary Medicinal Product Residues and Other Substances in Live Animals and Animal Products; EFSA Supporting Publication: Parma, Italy, 2018; Volume 15.

38. Report for 2017 on the Results from the Monitoring of Veterinary Medicinal Product Residues and Other Substances in Live Animals and Animal Products; EFSA Supporting Publication: Parma, Italy, 2019; Volume 16.

39. Report for 2018 on the Results from the Monitoring of Veterinary Medicinal Product Residues and Other Substances in Live Animals and Animal Products; EFSA Supporting Publication: Parma, Italy, 2020; Volume 17.

40. Tadesse, T.; Tadesse, T. Public Health Impacts of Antibiotic Residues in Foods of Animal Origin: A Review. Public Policy Adm. Res. 2017, 7, 6-11.

41. Bacanll, M.; Başaran, N. Importance of antibiotic residues in animal food. Food Chem. Toxicol. 2019, 125, 462-466. [CrossRef] [PubMed]

42. Veterinary Medicines Directorate Understanding the Population Correction Unit Used to Calculate Antibiotic Use in Food- Producing Animals; Veterinary Medicines Directorate: Addlestone, UK, 2016.

43. Darko, G.; Mensah, J.K.; Dapaah, S.S.; Odei, J. Estimated dietary exposure to veterinary residues in chicken and eggs. Int. J. Food Contam. 2015, 2, 16. [CrossRef]

44. Li, R.; Jay, J.A.; Stenstrom, M.K. Fate of antibiotic resistance genes and antibiotic-resistant bacteria in water resource recovery facilities. Water Environ. Res. 2019, 91, 5-20. [CrossRef]

45. US Department of Health and Human Services. Antibiotic Resistance Threats in the United States; CDC: Atlanta, GA, USA, 2013.

46. Muñoz, R.; Cornejo, J.; Maddaleno, A.; Araya-Jordá, N.C.; Iragüen, D.; Pizarro, N.; San Martín, B. Withdrawal times of oxytetracycline and tylosin in eggs of laying hens after oral administration. J. Food Prot. 2014, 77, 1017-1021. [CrossRef] [PubMed]

47. Xie, K.; Zhao, M.; Guo, H.; Zhang, X.; Sun, Y.; Li, A.; Xie, X.; Zhang, G.; Dai, G.; Wang, J. Determination and depletion of amoxicillin residues in eggs. Food Addit. Contam. Part A Chem. Anal. Control. Expo. Risk Assess. 2013, 30, 670-677. [CrossRef]

48. Gajda, A.; Nowacka-Kozak, E.; Gbylik-Sikorska, M.; Posyniak, A. Tetracycline antibiotics transfer from contaminated milk to dairy products and the effect of the skimming step and pasteurisation process on residue concentrations. Food Addit. Contam. Part A Chem. Anal. Control. Expo. Risk Assess. 2018, 35, 66-76. [CrossRef] [PubMed]

49. Goetting, V.; Lee, K.A.; Tell, L.A. Pharmacokinetics of veterinary drugs in laying hens and residues in eggs: A review of the literature. J. Vet. Pharmacol. Ther. 2011, 34, 521-556. [CrossRef] [PubMed]

50. Brennan, M.J.; Duncan, W.E.; Wartofsky, L.; Butler, V.M.; Wray, H.L. In vitro dissolution of calcium carbonate preparations. Calcif. Tissue Int. 1991, 49, 308-312. [CrossRef] [PubMed]

51. European Commission. Commission Decision 2002/657/EC. Off. J. Eur. Commun. 2002, L221, 8-36.

52. Wenzl, T.; Haedrich, J.; Schaechtele, A.; Robouch, P.; Stroka, J. Guidance Document on the Estimation of LOD and LOQ for Measurements in the Field of Contaminants in Feed and Food; JRC Technical Report; European Commission: Belgium, Brussels, 2016; EUR 28099 EN. 